\title{
Your Startup Team: Why Both Shared and Diverse Experiences Matter
}

\author{
Florence Honoré (University of Wisconsin-Madison)
}

KEYWORDS: Innovation, Startups, Diverse Entrepreneurial Teams.

Which kinds of startup teams will be more successful: people who've worked together in the past and share many experiences, or groups of individuals with different work histories and experiences? My research has shown that a cadre of founders with shared experiences and histories has a better shot at survival than teams with disparate experiences, but teams really performed when they include some of both.

My study focused on the work experience of about 6,000 founding teams in a sample of technology manufacturing startups. In particular, I looked at the variety of experience founders possessed (or their "within-founder experience variety") as well as the extent to which founders had worked together in the past. I found that the startups were more likely to survive when their founding teams combined the stability from members with across-team shared experiences with the innovativeness that flows from other teammates with experience variety.

This video summarizes my findings. For a copy of the full article, email me at honore@wisc.edu (mailto:honore@wisc.edu), or you can visit the article page of the journal's website here (https://journals.aom.org/doi/10.5465/amj.2018.1386) .

Link to video

Copyright ( $) 2021$ The Authors. Entrepreneur \& Innovation Exchange is published at EIX.org. This is an open access article under the terms of the Creative Commons Attribution-NoDerivs License, which permits use and distribution in any medium, provided the original work is properly cited and no modifications or adaptations are made. View EIX.org Authorship Terms at https://eix.org/terms 